\title{
VIRTUAL PATIENTS AS THE TOOLS OF PROFESSIONAL COMMUNICATIVE TRAINING IN THE US HIGHER MEDICAL EDUCATION
}

\author{
Lyubov Manyuk \\ Seniour Lecturer \\ Department of Latin and Foreign Languages \\ Danylo Halytsky Lviv National Medical University \\ 69 Pekarska str., Lviv, Ukraine, 79000 \\ lyubov.manyuk@gmail.com
}

\begin{abstract}
The system of higher medical education of the USA is characterized by the significant advance in the sphere of new technologies usage. The first computerized training programs for medical students were introduced in this country. Nowadays, new technologies including "virtual patients" (VP) are commonly used in undergraduate formal or hidden curriculum of US medical schools with the aim of professional and communicative training of future physicians. Thus, such valuable experience of the US medical education institutions may be useful for the development of higher medical education in other countries.

The paper presents the historical overview and describes the evolution of computerized programs, ICTs and virtual patients in the system of higher medical education of the USA; researches the ways of virtual patients' implementation in the structure of communicative and professional training in US medical schools and colleges; defines the notion of "virtual patient"; describes the types of VP and the methodology of their usage depending on the academic purpose; discusses the advantages, as well as the problems of VP usage in the curriculum and their possible solutions.
\end{abstract}

Keywords: virtual patient, ICT, USA, higher medical education, communicative training.

\section{Introduction}

The system of US higher medical education is characterized by significant advance in the sphere of new technologies usage for professional communicative training in particular. Modern technologies comprising the tools of information-communicative technologies (ICT) are used as the components of formal, non-formal and informal learning in the process of professional communicative training of US medical students. The most common ICT tools of professional communicative training include computer technologies, virtual patients (VP), virtual learning environments, electronic mobile devices, electronic social media (ESM) and other digital technologies and smart accessories that are the elements of formal and informal curriculums at higher medical education institutions (HMEI). Moreover, the listed technologies represent e-learning which is introduced at medical schools and colleges of the USA in the periods of pre-clinical and clinical training oriented on the development of professional and communicative skills.

\section{Theoretical background}

The proceedings of International and World conferences on the problems of professional communication and the use of new technologies and virtual patients, in particular, for this type of activity as well as the current scientific papers in the field of higher medical education and learning materials for medical educators form the theoretical basis of the research. The up-to-date data concerning the use of virtual patients (VPs) in training of future physicians for professional communication were retrieved from the official web-sites of acting US universities (NYU School of Medicine 2016; Ohio State University. College of Medicine, 2016; University of Illinois College of Medicine, 2016; Yele School of Medicine, 2016).

The analysis of the sources on the theme of the research proves the significant interest of Ukrainian and foreign scientists in the problem of computerized learning implementation and development [1]; the use of ICTs in the learning process [2, 3]; methodical and pedagogical aspects 
of future physicians' professional training and the use of new technologies for this kind of activity [4-8]; the use of VPs for communicative [9-11] and professional training [12-20].

The methodology of comparative pedagogy has been used in the process of the study. The systemic approach in combination with a factological one has been applied. The principles of continuity, connections, logics, objectiveness, integrity and informational comparison have been followed in the research.

\section{Aim and tasks of the research}

The aim of the paper is to study the ways of using virtual patients in professional communicative training of medical students at the universities of the USA. The following list of tasks was stated to attain this aim:

1) revealing the background of the computerized learning development and the evolution of information and communication technologies usage in the US medical education;

2) characterization of the notion and types of VPs;

3) determination of the ways and methods of the VPs use in the learning process at higher medical educational institutions including the training of future physicians for professional communicative and professional activity;

4) studying the obstacles and problems in the process of VP implementation as the components of curriculums;

5) assessing the current state of new technologies implementation at medical schools and colleges of the USA.

\section{Results and discussion}

The first attempts of computer-assisted learning in the medical field were realized at the end of 1960s in the USA by three main institutions, namely: University of Ohio [24], Massachusetts General Hospital and University of Illinois [3, 21-24].

The scientists who worked in the direction of computerization of the learning process at HMEI, followed an idea of educational modernization and creation of additional means of future physicians' professional training. The first attempts of researchers were aimed to create a computer program oriented on the development of interpersonal interaction skills of medical students, their communication with patients during the medical encounter. Such programs were created to imitate real patients and medical encounters and are known as "virtual patients" (VP) [23]. Before the emergence of the term "VP" the notion "computer model of clinical encounter" was used to characterize this program.

The term VP appeared in 1971 to determine the "interactive systems of modeling the clinical processes used in medical education" [25]. Before emergence of information technologies the paper case-technologies were used with this aim. Today, the VP conception combines scientific basis, modern computer technologies and innovative technologies of game-based learning. The learning process with the use of VP is based on the role interaction, according to which student can act as the doctor, observe the results of the diagnostic and treatment decisions and also bear responsibility for the results of performed actions. The reality of professional situation creates the special emotional atmosphere that optimizes the mastering of learning material and improves the quality of learning [17, 25].

According to the definition of American Association of Medical Colleges, VP is "a specific type of computer program that simulates real medical situations and gives a possibility to imitate the doctor in anamnesis collection, patient examination, diagnosis statement and treatment arrangement" [26]. The main components of VP include interactivity of the learning process and visual presentation of diseases and conditions. There are three forms of VP, namely:

1) situational tasks available on-line or on the disc;

2) virtual reality imitating the effect of real presence;

3) automated mannequin-robot constituted and sized as the real human. In professional communities the term "mannequin" is used for this type of VP. 
The most systems provide the linear interaction of students using the dialogues and feedback optimally approximated to life situations. In other words, VP is a computerized model of a patient which consists of:

1) received parameters;

2) simulation;

3) output result.

The received parameters include special possibilities of computer interaction between a student and a system by such tools as a mouse, keyboard or sensors on mannequins. Having received the input data, VP processor generates the response. Simulation is a program that functions on the base of certain physiological, pharmacological or communicative model. The output result is reflected by any visual, auricular or mechanical result of simulation and can have the form of oral response, face expression, gesture or information about the change of blood pressure, palpitation. The accuracy and reality of interaction depend on the quality of the equipment $[4,8,11,27]$.

Nowadays the most spread VP form is the one based on the linear-interactive activity using Internet. Thus, VP acts as a means of Web-supplemented learning, component of ICT infrastructure - cyberspace of higher medical education, formed by computer programs, servers, electronic social media, telemedical technologies, virtual worlds and learning environments.

VP have been used since 1960. Laboratory of computer sciences of General Massachusetts Hospital attempted to create computer programs modeling clinical cases. Such models of medical encounter, due to which students had a possibility to state hypotheses, receive and interpret information from patient and also practice the skills of diagnosis statement and treatment planning were particularly spread [27]. The examples of such systems are: CASE, CATS, GENESIS, INDEX, MATRIX, Mac Path, PLATO, Sim One, TES and other [23].

In 1965 the CASE (Computer-Aided Simulation of the Clinical Encounter) technology - imitation of medical encounter using the computer was introduced in Illinois university. Having seen the brief review of patient, reflected on terminal, student interacted with the program, using natural commands printed in the computer. The program provided logical answers for most requests. Such interaction was rather realistic and interesting, so students accepted it with enthusiasm [22].

The Programmed Logic for Automated Teaching Operations (PLATO), the system created at Illinois university, was the best one among the systems of that time, developed especially to support computer-oriented medical education. The experience of the institution and PLATO which used the authorized language TUTOR, formed the background for computer-oriented curriculum. The activities of the system included the compulsory and additional learning materials, exercises, based on CASE program, social consulting, differential diagnostics, communication with incurable patients, together with traditional clinical situations [23].

Despite the fact that virtual patients were created nearly forty years ago, they have not been widespread in the US educational paradigm until recently. According to the studies carried out in 2007 only $24 \%$ of American schools used VP in the learning process. However, due to their role as the safe learning tools that can be used during the long time and model different severe and complicated clinical cases, the ground for introduction of virtual patients as the obligatory components of HMEI curriculums was formed [15, 18].

The decrease of the number of hours for clinical training in curriculums, caused by the social biases concerned with the participation of real patients in the study, increase of requirements referring to the documentation of such medical procedures, could result in worsening of students' clinical skills. The solution of this situation was found after the technological progress of 1970s. The development of multimedia technologies took place in this time and a VP was created $[17,20]$.

The advantages of using VPs in medical education do not need verification for a long time. In addition to the improvement of active involvement in the learning activity they are also proved to enhance the level of knowledge, critical clinical thinking, and skills of decision 
making. But their use in the formal study of medical ethics, law and professionalism is still a prospective direction. The experiments using electronic VP prove their effectiveness in the training of ethical behavior and making ethical decisions [19]. VPs are appreciated by the students who consider the learning of professional issues as the necessary element of learning process at HMEI [10]. VP cannot be a single instrument of medical students training, but their possibilities are maximally used for the development of all types of interaction with patients. The comparative studies of the readiness of medical students to professional communication confirm significantly higher rates in students who underwent the formal communicative training at the Centers of Simulation of HMEI [28]. This type of learning includes both the technologies of e-learning and m-learning.

In most medical HMEI of the USA the standard patients (SP) are used for communicative training, but their use is characterized with the high cost and significant time outlays. In this context virtual patients have the list of advantages compared with SP and can be used as the main tools for professional communication training. The paper of Stevens describes one scenario of medical students training in medical history taking using VPs. The process of research included the examination and consultation of a VP whose image of the real size was projected on the wall of the room. The technical tools were comprised by two personal computers connected to the internet, projector, a tablet, two web-cameras (tracing the movement of medical student) and a microphone. Before the "encounter" the future physician learned the patient's data with the help of a tablet computer. VP included the programmed options of voiced answers and gestures as the responses to the students' requests developed on the basis of the videos of real medical encounters. As the result of the study the effectiveness of repeated safe controlled VP use for professional activity realized by communicative interaction with patients was proved [11].

The main problem of the assessment of doctor's professional skills, including the communicative abilities during the encounter is a standardization of these skills and the procedures as well as the means of their assessment. The Liaison Committee on Medical Education of the USA [29] introduced VP for the assessment of clinical experience that nowadays is rather spread method of medical training and assessment. However, such patients do not give a possibility for the physical presentation of the symptoms and diseases. At the same time the interaction with SP can be influenced by such factors as memory, fatigue, bias that can influence objectivity. The use and implementation of VPs into the learning process is realized using the comparison of its effectiveness, advantages or, on the contrary, disadvantages with SP.

VPs, available in the special Centers or on-line, can repeatedly demonstrate the clinical images, providing the possibility for students to revise and practice their skills, to compare their progress with each other. The special sound and visual possibilities of VPs demonstrate the murmur, derivations in respiration, etc. Other advantages of VPs are the interactivity of the learning process, active interaction of a student, based on cyclic process that includes real physical actions, observations, decisions, planning. VP provides the recognition of acquired theoretical knowledge in the real situation. Thus, there has been a necessity to elaborate different VPs able to model clinical cases, providing the realization of self-study, motivation of students and effectiveness of the learning process.

VP can be used in different pedagogical forms as supportive and complementary tools in the learning process, practicing of everyday communication with patients and solving the real problems linked to diagnosis statement [14]. They play an important role in higher medical education [30]. Moreover, VP are most effective as the instruments of communicative skills development [12]. The study proves that a well-designed VP model provides proper emotionality of medical students, signs of empathy, improves the quality of real interaction with patients [16].

VPs are most effective when used in combination with SP. It is worth noticing, that creating VP models oriented on the development of communicative interaction skills is one of technologically simplest procedures, but it is dependent on the author's idea and standard scenario that complicates the communicative process. However, despite the solitary disadvantag- 
es, VPs proved their effectiveness as the components of communicative and clinical training of future doctors. Compared to the students trained without the use of VP, students who studied with the help of VP means demonstrated much better results [15]. It served a stimulus for the research of the ways of VP implementation in the curriculums.

As it was noted above, VP proved their effectiveness as the instruments of professional communicative training. One of the studies carried out in 2001 proves it. The scientists created two different VP models for the same clinical situation, but one of them was based on the narrative approach with an accent on communicative interaction and the other one - on the model, oriented on the solution of situational problem. The significant difference between the output results of experimental groups was not revealed, but the students who experienced the narrative model, demonstrated better communicative skills. They used open questions, proper language tools, vocabulary and intonation. Thus, it has been recommended to use the narrative approach in the process of VP development [12].

The most significant difficulties in the process of VP implementation are the high cost and time consumption. The development of one model can cost thousands of dollars and requires nearly one year [13]. One of the solutions is the development of unified models and the common use of VPs. With this aim the series of organizations that work for VP creation were formed. The example of such projects is "e-ViP" [31] (electronic VP) that contains 320 models of the different clinical situations accessible for everyone without authorization. The project, financed by European Commission provides the research and implementation of VP to improve the learning process at HMEI [32-33] and develop communicative and clinical skills. Such projects created in the USA include vpSim [34] and physioSim.

VpSim is a commercial project with closed access in contrast to physioSim. PhysioSim gives the free access to information on the news, usage methods, research and VP models. The platform "i-Human Patients" [35] contains the rubric "Lessons" that includes 320 options of different medical encounters and different medical specialties: surgery, pediatrics, general medicine, gynecology, etc. The titles of lessons reflect the thematic sections and contain theoretical information on the spectrum of problems, connected with the topic of the lesson, recommended for study before the direct interaction with VP named "i-Human". The team of scientists designed a real verbal and non-verbal communication that is realized at stepped virtual procedure of medical encounter, including:

1) collection of anamnesis;

2) physical examination;

3) establishing of differential diagnosis that means determination of probable diagnosis, narrowing of the spectrum of possible options or at least exclusion of the life-threatening conditions;

4) prescription of diagnostic tests;

5) choice of confirming diagnostics method;

6) prescription of the treatment plan.

During this procedure students make decisions concerning the number and the content of questions of medical history, choice of the body parts for examination, options of possible diagnoses, types of necessary tests, interpretation of the results of the tests and decisions about the necessity of additional tests, establishing final diagnosis and planning of further actions [33].

A large number of projects, created for VP elaboration triggered the initiation of a consortium MedBiquitous that works for the creation of methodical recommendations on the spread and common use of VP that are available for free. However, VP is not a real human; it is a computer program guided by an artificial intellect and its reality, reliability and probability depend on the design and physical possibilities. As far as VP technologies are rather new, there are not many papers about the standards of their introduction into curriculums [13].

The automated interaction with VP gives a possibility to trace student's actions towards diagnosis statement. There are VP models in which interaction is realized orally using student's questions, VP's answers and computer-mediated interaction with the help of input of the data into the system using keyboard, choice of options, transfer of references, choice of actions from the list. 
The laboratory studies of Sendan prove the effectiveness of both models, but emphasize the fact that the first option provides the optimal approximation of virtual medical consultations, communicative contact and physical examination to the real situations. The scientists created a VP model that functions according to the first sample, providing a possibility of complete reflection of student's actions and a reliable assessment of these actions, respectively. The paper of the scientists also confirms that the activities in small groups of three persons are characterized by better results than individual activities. Thus, it proves the effectiveness of using VPs in the learning process at HMEI. The use of VP influences the process of future physicians' training improving the development of clinical and communicative skills.

The basic communicative strategies that characterize effective physician-patient communication are: listening, analysis and synthesis (reveling the problem), prognosis of actions, specification, metaphorization (replacement of complicated terms with the simpler ones, understandable for patients), tutorship, resuming [9]. The listed communicative strategies require developed communicative skills, acquired by medical students during the role games and learning activities with VPs.

The project, aimed at creation of VP library, was started at the medical school of Harvard. The project called «Virtual Patient Project» provided creation of VP that gave a possibility for: problem;

1) preliminary assessment of patient's condition according to his/her presentation of the

2) prescription of tests, necessary for diagnosis statement;

3) observation of the result;

4) regulation of thecontext-depending feedback.

The teachers who participated in this project received special conditions for the work at home and set number of hours in the individual teacher's plan [20].

Understanding of the importance of using VP for the purpose of communicative training of US future physicians is proved by a number of organizations, portals and institutions, created with the aim of improvement in this direction. One of examples is American Academy on Communication in Healthcare that has been investigating and teaching the aspects of interpersonal communication between medical students and doctors for more than thirty years. The application "DocCom", including 42 learning modules available on-line with the help of technical possibilities of telemedicine systems for video-conferences "WebOSCE" and electronic application "WebEncounter", designed for the practice and assessment of the distant medical consultations using the real SP are accessible on the web-portal of Academy.

The opposite side of new technologies usage in education should also be added.The appearance of new technologies and the development of e-learning influence and change the teaching paradigm, methodology of practical and seminar activities and lectures. As it was proved above, this process faces a lot of challenges in the context of HME.

\section{Conclusions}

Thus, the carried out research has revealed the following:

1. Computer technologies in medical education were firstly used in the USA. In this country a lot of computer learning programs and systems were designed and introduced in the learning process that was mainly used for facilitation, improvement and optimization of existent pedagogical means and methods.

2. Computer programs for the imitation of real patients and medical encounters are called virtual patients. There are three types of VP, namely:

1) situation problems;

2) virtual reality with imitation of the presence effect;

3) mannequins. The most spread form of interaction with VP is the linear-interactive connection in virtual environment using the input and output parameters as well as possibilities of artificial intellect.

3. VPs are used to support and supplement the process of everyday communicative interaction with patients and solutions of clinical problems, connected with diagnosis statement. 
4. There are a lot of challenges linked to organizational, learning-methodical and financial aspects of higher medical education on the way to VP implementation in formal communicative curriculums.

5. Despite the difficulties, the system of medical education in the USA is characterized by the significant advance in the field of ICTs, artificial intellect and virtual technologies, in particular VP, usage for the purpose of professional and communicative training of the future physicians.

The future direction of the research is the study of the state of the new technologies use in professional communicative training of medical students at higher medical education institutions of Ukraine.

\section{References}

[1] Voronkin, O. S. (2015). The perspectives of information and communication technology of education of students in higher educational institutions of Ukraine. Information technologies in education, 24, 81-106. Available at: http://ite.kspu.edu/Issue_24/p-81-106 doi: 10.14308/ite000568

[2] Manyuk, L. V. (2015). Student, Internet and Medical University. Distance education in higher educational institutions: innovation and psychologically pedagogical aspect. Book of scientific papers of International scientific methodical conference. Kharkiv: City Print, 152-156.

[3] Dev, P., Hoffer, E., Barnett, O. (2009). Computers in medical education. Master educator fellowship. UF Health: University of Florida, College of medicine. Available at: http://mef.med.ufl.edu/files/2009/10/ Computers-in-Medical-Education.pdf

[4] Abrahamson, S., Denson, J., Wolf, R. (1969). Effectiveness of a Simulator in Training Anesthesiology Residents. Academic Medicine, 44, 515-519. doi:10.1097/00001888-196906000-00006

[5] Hryn, V. K. Bassov, O. I., Sobolyev, D. V., Vorobjov, A. S. (2013). The implementation of the system of distance education in the practice of the family doctor [online] Ukrainian journal of surgery, 2 (21). Available at: http://www.mif-ua.com/archive/article/36339

[6] Liahotska, L., Liahotska, M. (2012). E-learning of doctors. Theory and methodology of educational management, 8. Available at: http://tme.umo.edu.ua/docs/8/16.pdf

[7] Moberg, T .F., Whitcomb, M. E. (1999). Educational technology to facilitate medical students' learning: background paper 2 of the medical school objectives project. Academic Medicine, 74 (10), 1146-1150. Available at: http://www.ncbi.nlm.nih.gov/pubmed/10536639 doi:10.1097/00001888-199910000-00020

[8] Ward, J., Gordon, J., Field, M., Lehmann, H. (2001). Communication and information technology in medical education. The Lancet, 357(9258), 792-796. Available at: http://www.ncbi.nlm.nih.gov/ pubmed/11253986 doi:10.1016/S0140-6736(00)04173-8

[9] Lazzari, C. (2013). Communication skills training for health care professionals. What is it all about? Medical Teacher, 35 (8), 700-701. Available at: http://www.tandfonline.com/doi/full/10.3109/014215 9X.2013.786172 doi 10.3109/0142159X.2013.786172

[10] McEvoy, M., Butler, B., MacCarrick, G. (2012). Teaching professionalism through virtual means. The Clinical Teacher 9(1), 32-36. Available at: http://www.ncbi.nlm.nih.gov/pubmed/22225890 doi: 10.1111/j.1743-498X.2011.00487.x

[11] Stevens A., Hernandez J., Johnsen K., et al. (2006). Scott The use of virtual patients to teach medical students history taking and communication skills. The American Journal of Surgery, 191(6), 806-811. Retrieved from: http://www.americanjournalofsurgery.com/article/S0002-9610(06)00204-2/abstract doi: 10.1016/ j.amjsurg.2006.03.002

[12] Bearman, M., Cesnik, B., Lidell, M. (2001). Random comparison of virtual patient models in the context of teaching communication skills. Medical Education, 35(9), 824-832. Available at: http://www.ncbi. nlm.nih.gov/pubmed/11555219 doi:10.1046/j.1365-2923.2001.00999.x 
[13] Cendan, J., Lok, B. (2012). The use of virtual patients in medical school curricula. AJP: Advances in Physiology Education, 36(1), 48-53. Available at: http:/www.ncbi.nlm.nih.gov/pmc/articles/ PMC3776425/ doi: 10.1152/advan.00054.2011

[14] Cook, D., Triola, M. (2009). Virtual patients: a critical literature review and proposed next steps. Medical Education, 43(4), 303-311. Available at: http://www.ncbi.nlm.nih.gov/pubmed/19335571 doi:10.1111/ j.1365-2923.2008.03286.x

[15] Cook, D., Erwin, P., Triola, M. (2010). Computerized virtual patients in health professions education: a systematic review and meta-analysis. Academic Medicine, 85(10), 1589-1602. Available at: http:// www.ncbi.nlm.nih.gov/pubmed/20703150 doi: 10.1097/ACM.0b013e3181edfe13

[16] Deladisma, A., Cohen, M., Stevens, A. et. al. (2007). Do medical students respond empathetically to a virtual patient? The American Journal of Surgery 193(6), 756-760. Available at: http://www.ncbi. nlm.nih.gov/pubmed/17512291 doi: 10.1016/j.amjsurg.2007.01.021

[17] Ellaway, R., Poulton, T., Fors, U. et. al. (2008). Albright Building a virtual patient commons. Medical Teacher, 30(2), 170-174. Available at: http://www.ncbi.nlm.nih.gov/pubmed/18464142 doi: 10.1080/01421590701874074

[18] Ellaway, R., Poulton, T., Smothers, V., Greene, P. (2009). Virtual patients come of age. Medical Teacher, 31 (8), 683-684. doi:10.1080/01421590903124765

[19] Hooper, C., Jivram, T., Law, S., Michell, A., Somasunderam, A. (2012). Using virtual patients to teach medical ethics, medical law and medical professionalism. Medical Teacher, 34 (8), 674-675. doi: $10.3109 / 0142159 x .2012 .689450$

[20] McGee, J. B., Neill, J., Goldman, L., Casey, E. (1998). Using multimedia virtual patients to enhance the clinical curriculum for medical students. Student Health Technol Inform, 52, 732-735. Available at: http://www.ncbi.nlm.nih.gov/pubmed/10384556

[21] The LSI Curriculum. Ohio State University College of Medicine. Available at: http://medicine. osu.edu/students/1si_curriculum/pages/index.aspx

[22] History of computing in medicine (2001). Prinston University, Department of computer sciences. Available at: http://www.cs.princeton.edu/courses/archive/spr02/cs495/History\%20of\%20Computing\%20in\%20Medicine.pdf

[23] Lashof, J., Banta, H., Pengov, E., Miike, L., Gardner, P., Pietz, L. (1979). Computer technology in medical education and assessment: Background report. Washington, DC: U.S. Government Printing Office. Available at: http://digital.library.unt.edu/ark:/67531/metadc39398/.

[24] University of Illinois College of Medicine. (2016) Available at: http://medicine.uic.edu/cms/One. aspx?portalId $=443021$ \&pageId $=32089924$

[25] Virtual patient. (2016). Pharmaceutical encyclopedia. Available at: http://www.pharmencyclopedia.com.ua/article/8063/virtualnij-paciyent

[26] Association of American Medical Colleges. (2016). Available at: https://www.aamc.org/

[27] Chodorow, S. (1996). Educators must take the electronic revolution seriously. Academic Medicine, 71 (3), 221-226. Available at: http://www.ncbi.nlm.nih.gov/pubmed/8607916 doi:10.1097/00001888199603000-00009

[28] Liew, S., Dutta, S., Sidhu, J., De-Alwis, R. et. al. (2014). Assessors for communication skills: SPs or healthcare professionals? Medical Teacher, 36 (7), 626-631. Available at: http://www.tandfonline.com/ doi/full/10.3109/0142159X.2014.899689 doi:10.3109/0142159X.2014.899689

[29] Liaison Committee on Medical Education. (2016). Functions and Structures of a Medical School. Standards for Accreditation of Medical Education Programs Leading to the M.D. Degree. Available at: http://www.lcme.org/ 
[30] Friedman, C., France, C., Drossman, D. (1991). A randomized comparison of alternative formats for clinical simulations. Medical Decision Making, 11(4), 265-272. Available at: http://www.ncbi.nlm.nih. gov/pubmed/1766329 doi:10.1177/0272989x9101100404

[31] Electronic Virtual patients. (2016). Available at: http://virtualpatients.eu/about/about-evip/

[32] NYU School of Medicine. Available at: http://www.med.nyu.edu/school/education-training

[33] Yele School of medicine. (2016). Official web-site. Available at: http://medicine.yale.edu/education/

[34] VP Sim. (2016). Available at: http://vpsim.pitt.edu

[35] i-Human Patients. (2016). Available at: http://www.i-human.com/cases/\#standard 